\title{
El pensamiento sobre la naturaleza en el Renacimiento
}

Teodoro Bustamante ${ }^{1}$

\begin{abstract}
RESUMEN
En eSTe ARTículo SE PRESENTA El PROCESO POR EL CUAL EL RENACIMIENTO IMPULSA dOS PROCESOS DEL DESARROLLO del pensamiento occidental. Por una Parte, la dimensión utópica, Que tiene expresiones en moro y erasmo, Y POR OTRA LA VISIÓN RACIONALISTA. El GÉRMEN DE ESTA PERSPECTIVA ES UbICAdo EN ROLleWINK. SE MUESTRA COMO LA PROMESA RENACENTISTA SE PIERde POR LA LUCHA POR El PODER, Y SE MUESTRA CON ELLO QUE LA VISIÓN ESTEREOTIPADA DE UN PENSAMIENTO DE LA NATURALEZA UNILATERAL QUE SE ATRIBUYE A OCCIDENTE ES MUCHO MÁS COMPLEJA, Y QUE PARA SUPERAR LOS PROBLEMAS ACTUALES DE LA RELACIÓN CON LA NATURALEZA CONVIENE REGRESAR A ESTAS FUentes QUe TIENEN TODAVÍA MUCHO QUE ENSEÑar PARA EL día DE HOY.
\end{abstract}

Palabras claves: Renacimiento, Racionalismo, Idealismo, Utopía, Filosofía de la naturaleza

Abstract

This ARTICle PRESENTS THE PROCESS BY WHICH THE RENAISSANCE BOOSTS TWO PROCESSES OF DEVELOPMENT OF WESTERN THOUGHT. IN THE ONE HAND, THE UTOPIAN DIMENSION THAT IS EXPRESSED THROUGH MORO AND ERASMO AND IN THE OTHER HAND THE RATIONAL VIEW. THE SEED OF THIS OUTLOOK IS LOCATED IN ROLLEWINK. THE ARTICLE SHOWS HOW THE RENAISSANCE PROMISE IS LOST BY THE POWER STRUGGLE AND SHOWS WITH IT, THAT A STEREOTYPICAL VIEW OF A NATURE UNILATERAL THOUGHT, TO BE ATTRIBUTED TO THE WEST, IS MORE COMPLEX, AND TO OVERCOME THE CURRENT PROBLEMS RELATIONSHIP WITH NATURE, IT'S BETTER TO GET BACK TO THESE SOURCES THAT ARE STILL TO TEACH A LOT, EVEN IN NOW DAYS.

Key words: Renaissance, Rationalism, Idealism, Utopia, Philosophy of nature.

1 Escuela de Antropología, Pontificia Universidad Católica del Ecuador. 
$\mathrm{E}$ ste trabajo pretende explorar el tema de las transformaciones que se producen durante el renacimiento en las concepciones que tiene Occidente sobre la Naturaleza con dos preguntas en mente. La primera es ¿qué de nuestra realidad actual es explicado por esta genealogía de nuestra cultura y de nuestro pensamiento? En segundo lugar, ¿en qué medida, ésta experiencia de cambio vivido en el renacimiento, nos ilumina frente a las transformaciones que hoy día vivimos? Para ello exploraremos algunos temas centrales:

\section{El problema de la Razón}

La concepción que predomina en Occidente es que el surgimiento de la Edad Moderna, se construye a partir de una redefinición de lo que es la razón, su lugar como elemento fundamental y única fuente de autoridad indiscutible. Se trataría de un proceso por el cual, el pensamiento básicamente teológico de la edad media cede terreno ante una crítica racional y científica que progresivamente logra descalificarlo y derrotarlo a través de las acusaciones de autoritarismo y superstición.

Desde este punto de vista, la construcción del mundo moderno es la construcción de un mundo de la razón, en el cual se establece una operatividad, una capacidad de manipular los elementos de la naturaleza a fin de atender a las necesidades - o deseos - de los seres humanos.

Los pasos de este proceso serían en realidad los pasos del desarrollo de la Ilustración, del pensamiento científico. El hito más importante sería la revolución copernicana potenciada por Galileo. La visión Occidental nos diría probablemente que a partir de este momento, no hace falta sino establecer la autonomía de la racionalidad científica para que, cuestionando una racionalidad dogmática, permitamos que las ideas se promulguen y difundan de acuerdo a sus propias luchas y a su capacidad de demostrarse gracias a la razón. (Muñoz, 2005: 30) Una vez dados estos pasos, parecería ser que el progreso, las Ciencias y la modernidad no son sino el fruto que naturalmente brota de la simiente de la razón que alcanza su fecunda productividad una vez que se desembaraza de las cadenas de la superstición, del oscurantismo y la represión.

Esta visión simplificada, es parcialmente cierta, pero lo que nos parece interesante es indagar sobre otros matices, que tal vez nos pueden permitir enriquecer la comprensión de esta dinámica.

Tal vez sea interesante preguntarnos si tan simples contraposiciones, entre lo racional y moderno y lo oscurantista medieval, no empobrece la dinámica del proceso. Para iniciar este debate puede ser útil plantearnos una pregunta respecto a una obra particularmente relevante. Nos referimos al trabajo de Rolewink (1993) que nos presenta, en lo que hoy día podríamos llamar una absoluta ingenuidad, la cronología de la historia de la humanidad. Con sus cálculos podemos llegar al conocimiento de que estamos en el año 7205 de la era humana.

La primera reacción de cualquier persona que se ha informado, por ejemplo, de los hallazgos de Atapuerca, sería la de perplejidad. ¿Cómo pudieron estar tan equivocados? ¿Cómo pudieron afirmar con tanta certeza un dato tan radicalmente equivocado? Semejante error no puede sino confirmarnos en nuestra superioridad. Pero tal vez conviene ver las cosas de otra manera. Por más equivocado que Rolewink haya estado, su argumentación tiene algo de especial: a pesar de que por más de mil años estuvieron a la vista de todos los datos que él usó, nadie, que se sepa, se dio el trabajo de sumar, y llegar a determinar la fecha exacta del inicio de la humanidad. Lo sorprendente aquí, es lo tardío del error. Con esto lo que pretendemos demostrar, es que Rolewink, no es una expresión de una continuidad del pensamiento de la edad media, es un precursor o es un exponente cimero de ese pensamiento que lo está llevando a nuevas cumbres. Nos repetimos la pregunta ¿Por qué nadie efectuó antes esos cálculos?

Un segundo matiz es el hecho de que el error de Rolewink es un error de una enorme fecundidad, por que lo que hace con ese error, es plantearnos una pregunta revolucionaria, tanto por sus consecuencias, como por sus presupuestos. Es revolucionario por que simple y llanamente 
si nadie hubiese hecho esos cálculos, nadie hubiese sentido la necesidad de confrontarlos con otros métodos, con otras perspectivas. Rolewink está lanzando una pregunta. Sin ese tipo de preguntas no puede construirse la Ciencia.

Es también revolucionario por un cambio implícito en el formularse estas preguntas. Este cambio es establecer la pertinencia, la relación entre el cálculo aritmético de sentido común y la revelación divina. Nada más evidente que aplicar a las escrituras sagradas la lógica, la razón.

Esto implica que el mundo de la revelación y el de la comprensión humana, no están divorciados. No corresponden a esferas separadas sino que están comunicadas y es relevante para el ser humano usar su razón, en este caso su capacidad aritmética para entender el mundo, del cual forma parte inextricable la revelación y los acontecimientos centrales del pecado y la salvación.

Es en este sentido un precursor de las tareas de la ciencia. Pero la constitución de una esfera de la Ciencia es en realidad un proceso que no sólo es largo, sino que tiene además una serie de dinámicas internas que queremos comentar. ${ }^{2}$

Para ello, tal vez nos resulta útil contrastar la certidumbre del calendario Rolewinkiano, que sin dudas y con cuentas ciertas nos señala el orden de toda la historia relevante de la humanidad. Mientras que Nicolás Copérnico (1543) años después, presenta su modelo de los movimientos planetarios, no como una realidad, sino como un simple artificio de cálculo para dar cuenta y volver a entender los ordenados movimientos que parecían caóticos. Contrastemos, la seguridad del autor que afirma aquello de lo cual nosotros nos reímos, con la prudencia y humildad del que afirma lo que nosotros hoy damos por seguro y cierto.

Copérnico con recelo le escribe al Papa presentando una obra como un dispositivo de cálculo, tal vez sospechando ya que su obra sería censurada y prohibida. Pero aquí vienen pequeños detalles significativos. Copérinico es prohibido casi en una confrontación con Galileo (1623) muchos años después de la muerte del primero. Esto nos indica algo, y es que el significado, que nosotros damos a la concepción copernicana, no es todavía identificado durante su vida, y por lo mismo no es reprimido.

Pero tal vez aquí conviene detenernos un poco más en las diferencias y continuidades de estas dos figuras: Copérnico y Galileo. Galileo, en un sentido es el verdadero innovador. Pues es él quien introduce una serie de cambios en la aproximación a los hechos a la tarea explicativa. Es él quien utiliza por una parte la medida como un elemento central de su explicación de la realidad, y es por otra parte alguien que está averiguando y examinando frecuentemente las aplicaciones prácticas de sus conocimientos. Baste para ejemplo sus negociaciones con las autoridades florentinas, para recibir ingresos por sus desarrollos del telescopio, pero también por su perspectiva del uso de tal dispositivo, y concretamente del uso militar que podría tener.

En Copérnico, en cambio, nos topamos con alguien que no ha desarrollado tanto la perspectiva experimental y que se acerca a su reflexión desde otro punto de vista. Aquel que podríamos llamar teórico. En efecto, su preocupación central es encontrar una armonía explicativa en los astros. Búsqueda que no está lejos de la búsqueda estética de la perfección. Recordemos que las preguntas que él se formula, se derivan de la insuficiencia de las explicaciones ptoloméicas, que explicaban los movimientos planetarios a partir de la geometría de las figuras perfectas. El dialogo, el debate de Copérnico, parte de la teoría y del descubrimiento en ella de las leyes perfectas. El problema práctico es secundario si es que aparece en algún lado.

2 En este sentido corresponde a un programa Tomista, de unificar Ciencia y Fe. Posición que además será dejada luego por la tradición iniciada por Ockamp, que señala la necesidad de respetar la autonomía del mundo sensible. 


\section{¿La razón contemplativa?}

Se trata de lo que por falta de mejor expresión, describiré como la función contemplativa de la razón. El pensamiento, la reflexión, no tiene una utilidad práctica. La jerarquía de las disciplinas Universitarias o enciclopédicas ya nos señala la desvalorización expresa de lo práctico. La razón, tiene por fin ser parte del proceso de conocimiento de la divinidad. Ante este fin supremo, todas las dimensiones prácticas parecen nimias.

Desde el punto de vista de Occidente la revalorización de la razón a fines de la edad media, parece ser el embrión de nuestra racionalidad científico técnica potenciada en una ética utilitarista. Pero tal vez esto es no entender lo que realmente sucedía. Me parece ilustrativo, señalar otro hecho que corresponde a los que en ese entonces se producían a nivel espiritual.

Me refiero al auge, al brillo que también adquiere en esos siglos el pensamiento místico a través del trabajo de Diego Estrella, Fray Luis de Granada, San Juan de la Cruz, Teresa de Avila, Fray Luis de León, principalmente. Desde la visión de comienzos del siglo XXI podría parecer que se trata de dos corrientes divergentes dentro de una misma época, Quisiera explorar la posibilidad de que tal oposición sea solamente aparente. En efecto tanto el uso de la razón, como la experiencia mística, implican algo que me parece compartido frente a la revelación escrita, y codificada por la iglesia. El individuo requiere, necesita algo adicional en la búsqueda de la divinidad: algo más personal; la búsqueda personal. En el un caso es el uso de una de mis facultades que tiene un estatuto especial: la razón. En el otro, hay una disciplina y búsqueda más total que involucra la afectividad y a toda la persona, pero que por ello mismo es también individual.

Desde nuestro punto de vista de Occidente del siglo XXI, la afirmación de que la razón es utilizada como un mecanismo para acercarnos a Dios puede parecer como una justificación que utilizaban las mentes inquietas para poder continuar sus búsquedas en un ambiente represivo. Sospechamos que tal lectura es solamente la proyección de nuestra visión del mundo en una época diferente.

Creemos que puede ser fecundo plantearnos la hipótesis de que no, de que la afirmación de que la razón era una búsqueda de Dios no era una justificación. Era el argumento honesto de estas personas y además probablemente la descripción de su propia experiencia.

En Occidente, la Ciencia y todo nuevo descubrimiento es valorado sobre todo a nivel de las utilidades y sus implicaciones prácticas. Esto es al menos el planteamiento de Bacon (15611623). Pero sospechamos que Copérnico frente a su descubrimiento siente fundamentalmente una experiencia estética. Está vislumbrando un orden, una realidad superior a él mismo. Se trata de una relación con la razón que es compartida por otros Científicos; por un matemático del calibre de Pacal y no está ausente de Newton. Se trata de una relación en la cual la razón produce un sobrecogimiento frente a aquello que muestra y que revela. Sobrecogimiento que en algo recuerda la experiencia del místico frente a la divinidad que se le muestra.

Otra forma de expresar esta convergencia, es indicar, que las dos visiones tienen como efecto la invasión del mundo cotidiano por el mundo del orden. Frente a una realidad Social en la cual el orden divino, expresado en la escritura, aparece como recluido en una institucionalidad ritualreligiosa que lo mantiene y afirma dentro de un mundo en conflicto y en desorden. Un mundo que es, recogiendo un cierto contenido platónico, un obstáculo, una trampa para acceder a la verdad.

Frente a ello surge, por ejemplo, la experiencia de San Juan de la Cruz, en la que los matorrales los campos y todo lo tocado por la divinidad, queda transformado. De manera similar, el filósof o que descubre que la creación misma es otro texto ${ }^{3}$ (Campanella, 1967, 1638) y el original del

3 Las fuentes de esta idea son múltiples incluyen a Campanella Metafísica numeral 1066, Quien allí mismo se refiere a varios santos: (Santa Brígida, San Antonio, San Bernardo, San Juan Crisóstomo) 
mensaje y la manifestación divina. Este mensaje que abre las puertas del desarrollo científico, esla forma en que pensadores de la alta edad media como Petrarca o San Buenaventura, recogen la tradición griega, latina y el importante rol de Salomón en la tradición hebrea.

\section{De la Ciencia de la Fe a la Fe en la Ciencia}

Esto nos puede llevar a otra idea. Nos referimos al hecho de que nos parece que a finales de la edad media y casi diríamos durante la gestación del renacimiento, se produce un cierto cambio del contenido de la Fe Cristiana. El mundo cotidiano, de las cosas prácticas, comienza a ser reconocido como parte del mismo mundo de la parusía, de la transformación.

El que anteriormente no ha sido necesario ni relevante, contar los años de las generaciones bíblicas, no nos habla de la pereza aritmética de mil años de cristiandad. Nos habla de la división mental entre el mundo de lo divino, por una parte. Incomprensible en si mismo y respecto al cual la relación fundamental no es la de comprenderlo sino la de adherirse a él. Por otra parte está un mundo concreto en el cual la razón se orienta fundamentalmente a lo práctico. En este terreno la mayor tarea es demostrar a los disidentes, esto es a los herejes y ateos sus errores en materia teológica, lo cual lleva a organizar un patrón universal de lo sagrado y lo revelado. Estandarizar una doctrina. Nos parece que estamos frente a un fenómeno especial y este es el de la unificación de la comprensión del mundo, la creación de una expectativa de que el orden del todo es uno sólo.

Sospechamos que el discurso teológico al fines de la edad media, está en un momento distinto. Ya ha superado las conflictivos momentos iniciales, se ha consolidado una dogmática, y luego de la dramática discusión en torno al credo, parece haber un corpus doctrinario establecido. Esto parece haber sido logrado en el intervalo de lo que podríamos llamar la tregua herética entre el final de los Cataros y el inicio del movimiento Hussita.

Pero a la vez el debate teológico se hace más exigente. La tradición judeo-cristiana tiene, para ese entonces, otros dos competidores que son capaces de elaborar y producir discursos Teológicos Universalistas. La Iglesia Griega y el Islam. Adicionalmente el propio Cristianismo Romano, como su nombre lo indica es una síntesis de una revelación escrita, (la judía) complementada por unos hechos que rompen parcialmente con esa tradición, (El cristianismo y en especial la visión Paulina) a la cual se agrega una herencia Romana e Imperial. Se hace necesaria una síntesis que no puede desconocer la vertiente Clásica y esta vertiente llega con nuevas fuerzas a través de los pensadores árabes (y judíos) de España. El pensamiento y la tradición Agustiniana parece entenderse bien con Platón, pero Aristóteles plantea y requiere todo un nuevo trabajo de síntesis.

Esta síntesis, tiene un nombre: la suma y en concreto la Suma Teológica de Santo Tomas. Esto es la creación de una estructura que tiene pretensiones de totalidad. Nos parece también interesante señalar como de la suma teológica se pasa a la suma lógica (Ockam, 1951). Casi en lo que parecería respuesta y superación de Santo Tomas surge otra visión, preocupada por el acto mismo del conocer y por la autonomía del mundo sensible. De ser una pesada sombra sobre la realidad esencial en la concepción agustiniana, pasa a ser parte de un mundo que es en si revelación divina, para llegar a ser un mundo autónomo y legitimo en sí mismo.

La fe de fines del medioevo, nos parece que tiene características muy importantes para poder permitir el surgimiento de lo moderno, de la ilustración. El primer paso es el convencimiento de que existe la explicación del orden en nuestro mundo sensible y que este es digno de ser conocido y más aun que su conocimiento, es una tarea importante, privilegiada del estar del hombre en la tierra. Tenemos así argumentaciones como por ejemplo la de Erasmo que combina la construcción teológica con otra argumentación paralela y humanista (Fuertes, 2002: 372). 
Casi imperceptiblemente se nos está haciendo presente una afirmación, típicamente moderna, y esta es que aquello que le da un estatuto diferenciado y privilegiado al ser humano es su calidad racional. Tanto es esto así, que uno de los productos típicos de la modernidad nos permite autobautizarnos como homo sapiens.

Creemos que es pertinente destacar que esta armonía entre Fe y razón es indispensable para la modernidad, hasta el punto de que la razón pasa poco a poco a ser la nueva depositaria de la $\mathrm{Fe}$. Nos atreveríamos a decir que el mundo moderno, que primero divide al mundo en un ámbito de $\mathrm{Fe}$, y otro de Ciencia, en realidad pasa luego a incluir a la fe dentro de la Ciencia. El hombre moderno cree, tiene fe absoluta y casi ciega en la razón. Le expropió a la religión no sólo el monopolio de la Fe sino todo derecho legítimo a esgrimirla, dejando tal vez un pequeño ámbito de consuelo subjetivo en el cual todavía es permitida legítimamente.

Desde un punto de vista del siglo XXI, probablemente se nos respondería que no se puede establecer semejante paralelo. El materialismo científico de los siglos XIX, XX y XXI no tiene Fe en la Ciencia, tanto es así que la Ciencia está siempre abierta al debate, y la relación que tenemos con las leyes científicas no puede compararse con la subjetividad de la adhesión a una Fe. Mientras que la Ciencia es Objetiva, la Fe es subjetiva y por lo tanto no se puede probar (ver por ejemplo Marinas, 2005).

\section{El Individuo y la Subjetividad}

Esta observación nos parece que introduce un nuevo tema fascinante: En todo este proceso está surgiendo y se está desarrollando una nueva subjetividad. Las versiones más usuales plantean que en el utilitarismo ético al estilo de Bantham y Mill, o bien al estilo Voltaire, plantean una afirmación del individuo.

Se nos dice que es la modernidad en la cual el individuo puede afirmar su derecho al bienestar que incluye básicamente el máximo placer y el mínimo dolor en contra de las visiones religiosas que de manera disyuntiva nos plantean siempre el camino del dolor y el sacrificio para acceder a la salvación eterna, o el del placer mundano que nos conduce al fuego eterno, al rechinar y crujir de dientes.

El símbolo más elaborado de esto sería tal vez, la pintura del Bosco en la cual se ordena el mundo de lo sensual ligándolo a los tormentos del castigo que trae consigo, alejándonos del mundo de la salvación, la disyuntiva entre el bien y el mal. Si recorremos su obra, en la cual vemos tan explicitas amonestaciones sobre el mundo del pecado como son por ejemplo los pecados capitales, parecería que todo calza perfectamente bien en el discurso de una voluntad de reprimir la pulsión del deseo para someterla, incluso para eliminarla.

Hay sin embargo algo que nos parece excesivamente simple, y demasiado mecánico en tal descripción. Tenemos la impresión de que hay mucho de bivalencia, de paradoja en este mensaje. Comencemos con el Jardín de las delicias. ¿Son los cuerpos desnudos allí retratados un discurso que muestra la corrupción y lo perverso de la sensualidad? ¿Es ese lanzarse desnudos en la naturaleza a compartir con animales bellos los árboles, el agua y la luz, una imagen de la corrupción? Tanta atención y tan armónica presentación de la desnudez humana nos parece que no es posible sino es a partir de una sensibilidad que admira y vive la sensualidad. Más aún, la dimensión desbordante en la cual no solamente vemos un desnudo aislado, sino una población entera, y que además de manera clara y explicita incluye la caricia, el abrazo erótico. Nos parece que nos habla de algo distinto. No es el lenguaje visual para hablarnos de lo repugnante que es el sexo.

Pero tampoco podemos pasar por alto el otro polo del mensaje visual, los seres torturados, un lado inverso al anterior en el cual, no solamente las personas están siendo quemadas, sino que hay una especial atención casi diríamos sádo-masoquista a la sexualidad de sus cuerpos que es plenamente explotado para causar, no sólo dolor sino denigración. 
El mundo animal en este aspecto se presenta con todo su potencial monstruoso: animales que devoran personas, las violan, las torturan y aún más parecería que son las personas que se convierten en monstruos. Todo cargado de sexualidad.

Casi nos parece que toda la pintura del Bosco es una pintura sobre el erotismo que es presentada en su versión idílica paradisíaca: la versión de antes de la caída y se contrapesa con la otra, con el erotismo perverso, sádico, torturador. Indudablemente cuadros de tal riqueza de componentes pueden ser leídos de muchas maneras pero quisiéramos agregar que percibimos en el polo perverso, una enorme presencia, no del erotismo, sino de la codicia. Las imágenes del asaltante, de los regateadores, de los negociantes, son los verdaderos portadores de la fuerza perversa.

Retomemos otra pista, esta ya en el terreno literario. Si regresamos a Salamanca, podemos detenernos unos momentos en los versos de un ex rector de esta Universidad: Fray Luis de León, que no sólo habla de los paisajes, y de lo buena que es "la retirada vida de los pocos sabios que en el mundo han sido" (Luis de León, 1990), sino que además produce versos en los cuales se refiere expresamente al "no se que" de los pechos femeninos. Esto para no mencionar la literatura mística toda que habla del encuentro con la divinidad en un lenguaje cargado de erotismo.

Nos parece que al contrario de lo que pudiera parecer, este es un momento en la historia de la humanidad en que Eros está presente y pujando por ser reconocido. La dificultad para darle un sitio no debe ser atribuida de manera mecánica a la espiritualidad de fines de la edad media, sino a una realidad conflictiva que incluso tendrá algunas de sus manifestaciones más extremas muy ligadas al desarrollo del capitalismo y la modernidad: el espíritu protestante, el calvinismo, entre otros. Pero tal vez puede ser interesante colocar esta discusión en una perspectiva más amplia. En realidad el tema de la sexualidad y la necesidad de subordinarla a pautas culturales no es un problema específico del cristianismo medieval. Las tradiciones culturales que expresamente incentivan la abstinencia sexual como condición para llegar a formas de conocimiento especial, son numerosas. Incluyen desde el Chamanismo amazónico, hasta muchas tradiciones orientales. Inclusive en la tradición Cristiana, probablemente los momentos culminantes de la ideología anti-sexual se ubican en otros momentos históricos, concretamente en los primeros siglos del cristianismo, en los cuales una interpretación literal de San Pablo determina que Orígenes opte por su castración en el siglo II y que esta sea propugnada por los Velencianos. También nos ayuda a construir una mejor perspectiva el hecho de que la ideología de la castración reaparece en diversos momentos de la historia. Por ejemplo, en la agitada Rusia del siglo XVIII, en la cual aparecen predicadores de muchos tipos incluyendo un movimiento de castrados, los skopsi, que en 1772 logran reclutar y castrar a más de 600 adherentes. En realidad, el conflicto de la cultura con la sexualidad atraviesa a la humanidad y nuestras soluciones, basadas en la ética utilitarista. No son ni totalmente originales ni carentes de tensiones.

Pero esto no quiere decir que el renacimiento y el final de la edad media no tengan algunas particularidades que merecen ser comentadas. Desde nuestro punto de vista, algo más específico es lo que surge entorno a la estandarización de la confesión. La elaboración de procedimientos fijos de interrogación al yo en la búsqueda del pecado, es un proceso que organiza la introspección, como responsabilidad ética, como responsabilidad de la individualidad. Estamos hablando de una técnica de individuación. Tal vez no hay nada más individualizante que el pecado de confesión individual. Ya no es suficiente nuestra participación en el pecado original a través del cual compartimos una circunstancia humana, se hace necesario construir una responsabilidad del individuo. Es el anuncio del programa de la introspección, que no será realizado en realidad plenamente hasta Freud. Y esto no se realiza en una continuación de un debate de defensa de un lugar para Eros y para el sexo, en una sociedad que ya era plenamente moderna. 


\section{Del auto de Fe a la Guiguilliotina}

El problema del individuo a fines de la edad media, nos desconcierta también por el desarrollo de una nueva institución, nos referimos a la Inquisición. Desde un cierto punto de vista podríamos decir que es la realización, esta si exitosa del programa del lado izquierdo de los cuadros del Bosco: la realización en la Tierra de las fantasías infernales.

También respecto a este tema, creemos que es conveniente, ubicar las cosas en términos históricos. La intolerancia religiosa no es invento medieval, ni del renacimiento. La tradición Cristiana ya tiene en el siglo XV una largo trayecto de persecuciones, tenemos las guerras contra los Cátaros al otro lado de los Pirineos, la persecución a los herejes, que inauguran, con la muerte de Prisciliano, la dinámica de perseguir por razones religiosas en el Cristianismo. Pero esto a su vez es compartido por la tradición mahometana que en la propia Península Ibérica no deja de derramar abundante sangre mora por razones de luchas religiosas. Y todo esto a su vez no es sino una moderada intransigencia frente a los textos del Levítico que exigen la práctica del anatema, es decir el genocidio con valor religioso.

Tampoco es este siglo el que inaugura las deportaciones por motivos religiosos, ya los propios conflictos del mundo islámico en España, habían llevado a expulsiones masivas entre las diversas doctrinas del Islam (García de Cortazar, 1988). Todo esto, sin embargo, no puede negar el hecho de que la inquisición si es un fenómeno único pues es la primera vez que se organiza un aparato permanente, en el cual está legitimada la tortura. Pero tal vez lo más interesante de este proceso es que la persecución no va ya a los participantes en ciertos ritos (judaísmo) o en ciertas adhesiones (luchas anti heréticas), sino que buscan inspeccionar exhaustivamente el interior de la persona, casi hasta encontrar las culpas de las cuales el investigado no es conciente.

Hay en esto un contenido de dominación, en el cual no falta una dosis de sádico rechazo al otro. En esto la modernidad recoge algunos elementos presentes en la Edad Media pero los lleva a una potencia nunca antes encontrada. No nos olvidemos que es a partir del inicio de la modernidad que el Occidente Cristiano lleva a las guerras de religión a un nivel nuevo. Las guerras por las convicciones luego se convierten en guerras políticas y el terror oscurantista de la iglesia es sobrepasado por el terror democrático, por el terror revolucionario, por el terror al líder.

\section{Un poquito más de Historia}

Pero ya que hemos introducido ciertos elementos históricos acotemos otros que nos parecen relevantes del momento de la historia en el cual se yergue este discurso.

Todo el renacimiento está marcado por el debate en torno a la autoridad papal. Las resistencias al Papa son sistemáticas y llevan a las tensiones de un Dante, que sin embargo se re-identifica y ve la necesidad de una unificación del poder Cristiano. Poder que sin embargo en su proyecto más monumental: La Basílica de San Pedro, evidencia ante personajes como el propio Erasmo, sus pies de barro, y que llevan a una disidencia de variados tintes y matices que comienzan a multiplicarse.

Se trata de dos elementos que convergen. Por una parte, la afirmación algo hedonista e individualista de un Maquiavelo que más que proponer un mundo de la lucha por el dominio en la cual el único límite es la fuerza de los otros, lo que está haciendo es proclamando una vieja realidad, que la utopía del Imperio Cristiano solo había enmascarado. Por otra parte, la corte papal parecía desde varios puntos de vista, también inspirada en el Maquivelo que se denunciaba.

Los terrenos de estas luchas eran varios. Por una parte el Papa que se enfrenta recurrentemente al emperador, pero este a su vez debe enfrentarse con frecuencia a los reyes, algunos de los cuales van consolidando tal nivel de poder que el Emperador tiene una ambigua situación frente a ellos. 
Pero el conflicto no es sólo entre Papado e Imperio. Pronto, la propia Iglesia se ve atravesada por la división: dos y hasta tres Papas simultáneos en el período que va de 1378 a 1417 erosionan la idea de la unidad. En realidad hieren de muerte a la idea de un Cristiandad Unificada (Ruggiero, 1971).

\section{Una unificación fallida}

Sin embargo hay un momento especial, la esperanza brilla de nuevo. Se trata de la coronación de Carlos V de Alemania, a la vez Carlos primero de España. Lo especial de este momento se debe a varias circunstancias. Se trata de un emperador que no sólo expresa un acuerdo con el pontífice y por lo tanto ilustra la posibilidad de eliminar las guerras y la rivalidades entre Papa y Emperador, sino que es además un rey tan importante que en sus dominios no se pone el sol.

Parece presentarse un futuro resplandeciente. Pero es resplandeciente no solo por que la acumulación de poder en Carlos $\mathrm{V}$ permite vislumbrar el fin de las rivalidades al interior de la cristiandad, sino que además, parecería ser que el hecho de que se ha completado el conocimiento del mundo (descubrimiento de América y circunvalación del globo) parece anunciar la culminación de un proceso histórico y casi escatológico: el fin de la edad del hierro, la edad de la guerra, del rechinar de dientes y de las lágrimas, para inaugurar otra edad de oro que probablemente sería la preparación de la reconstrucción de la nueva Jerusalén anunciada, la preparación de la parusía; transformación del mundo creado.

Sospechamos que en las mentes más inquietas de ese entonces hay preguntas que se refieren a la búsqueda de un sentido en los hechos históricos. Las mentes con sensibilidad humanista como Vitoria, ven en el descubrimiento de América un rencuentro con una parte de la humanidad perdida. Proclama con esto que nuestra especie; la descendencia de Adán, no estaba completa hasta que no se haya producido este re-encuentro. Re-encuentro que tiene así un sentido cósmico, en cuanto abre las puertas para que una vez reunidos los hijos de Adán podamos salir de la condena que él nos legó.

Sin embargo, la comprensión de lo que realmente sucede en este tiempo tiene que haber sido muy difícil, pues si bien se ha recuperado la mitad perdida de la humanidad y la caída de Granada anuncia la fuerza de la Cristiandad, hay otros acontecimientos que en breve tiempo seguramente generaban más angustias e interrogantes en torno a la pregunta sobre el sentido de ese momento histórico.

Por una parte la victoria de la Cristiandad es mucho menos consistente de lo que parece. Casi al mismo tiempo que los Reinos Cristianos de España arrojan a los moros de España, Otros reyes Cristianos se ven desplazados o muertos por la expansión musulmana que ahora es impulsada por el Imperio Otomano. La Cristiandad ufana de sus reconquistas, debe pronto enfrentar la penetración Turca hasta las puertas de Viena y a pesar de la victoria de Lepanto, perderá pronto el enclave de Túnez.

Pero no sólo esta particularidad marca este momento histórico. Hay una herencia que sospechamos marca la realidad también con mucha fuerza. Europa aún no se ha recuperado plenamente de la peste Negra. Y en realidad, del conjunto de pestes del siglo XIV. Una Marea de muerte ha terminado tal vez a un tercio de la población europea y en algunos registros se nos habla de cómo la peste se lleva a la mitad de los miembros de ciertos gremios urbanos (Ruggiero, 1971).

La dimensión de los hechos que describimos: un mundo entero que se descubre, una catástrofe demográfica, cambios gigantescos en las alineaciones de poder, a los que se unen descubrimientos increíbles en las ciencias, son la situación ideal para pensar que un nuevo mundo está a punto de nacer. La esperanza es en algunos autores clara, probablemente Erasmo, y Moro, son sus mejores exponentes. 
Pero al mismo tiempo vemos que esta aurora que se enuncia, está desde su inicio empañada. No sólo las guerras de religión y el cisma de la cristiandad avanzan sin solución posible, sino que más aún. Tan pronto como Carlos I logra la coronación Imperial, Francisco I de Francia inicia la lucha contra el Imperio y busca como aliados a los propios Turcos.

Desde nuestro tiempo podríamos decir que si es cierto, un nuevo tiempo había nacido, pero no fue una edad del oro. La Edad Moderna, nace con más sangre que la Edad Media, sangre en guerras hacia fuera, muerte en su expansión por el mundo, pero también sangre en las luchas religiosas, en las guerras por el poder, en las persecuciones, en el terror, en la tortura.

Sin embargo la historia de Erasmo, no era solamente una Historia Humana. Como buena Historia cristiana se trataba de una Historia cósmica que involucra a la creación entera y por lo tanto también a las otras criaturas, sean estas animales o plantas. Conviene entonces que nos hagamos algunas preguntas sobre la comprensión dela vida.

\section{El Mundo de la Vida}

La búsqueda de la perfección que llevó a Copérnico a pensar en las órbitas, que llevo a Pascal, a avanzar en las matemáticas y a Newton a hablarnos de que el lenguaje de las matemáticas sería el lenguaje de Dios, revolucionó el mundo. En la biología tenemos también un proceso similar, en el cual ésta admiración por el texto dela creación lleva a una investigación que termina por destronar la concepción creacionista. En este caso, el eje está conformado en primer lugar por un Lineo que buscando el orden divino en la diversidad de la vida, proporciona en método clasificatorio que luego permitiría el gigantesco trabajo de Buffon, que le da los materiales a Lamark para comenzar a negar la inmóvil perfección del mundo animal y comenzar a insinuar el conflictivo mundo de la evolución que será madurado y difundido después por Darwin y Wallace.

Se crea así la visión moderna de la vida. Esto es, una naturaleza en competencia, al igual que el ser humano. Esto implica que la magnificencia de la realidad no proviene del poder y del orden, si no en cierta medida de la lucha del conflicto en el desorden.

Si a esto unimos el avance de la ciencia, la tecnología y el sistema económico mundial que proporciona inconmensurables estímulos para producir riqueza, se nos configura el sitio del hombre en este mundo natural, el sitio del héroe prometéico que lucha y vence a la Naturaleza para producir el mundo humano de la riqueza.

\section{¿Una nueva oportunidad renacentista?}

La situación actual, en la que el ser humano se ha adueñado de más de la mitad de la fotosíntesis que se produce en el planeta, se ha afectado al propio sistema de regulación climática y que se ha impulsado procesos de extinción de especies más veloces que los mayores cambios geológicos, parecerían decirnos que el anuncio de la edad de oro, que en el renacimiento se pregonaba, no sólo no se ha cumplido sino que estaríamos aun peor en nuestra relación con la naturaleza. La victoria que sobre ella hemos logrado parecería convertirse en una victoria pírrica. Estamos peor que antes del combate.

Pero dado que ha surgido una nueva sensibilidad, dado que la conciencia sobre la necesidad de una nueva relación con la Naturaleza se ha hecho presente, parecería que ahora tal vez en un segundo intento, podremos lograr que se cumpla la promesa del renacimiento: la nueva edad de oro. Ante la aguda crisis que ya reconocemos en nuestras relaciones con el ambiente, ante el hecho de que la globalización es ya una realidad y que por varios mecanismos estamos ya creando instituciones de gobierno mundial. Ante el hecho de que las ciencias ya reconocen las limitaciones de su empirismo y mecanicismo positivista. Parece que ahora si estamos a las puertas de nuestra esperada edad del oro. 
Sin embargo el contraste entre los sueños renacentistas y la realidad de la modernidad, son una poderosa voz que nos advierte de lo ingenuas que pueden ser nuestras esperanzas si es que solamente nos dejamos llevar por la expectativa de que el tiempo ha madurado, de que se ha producido ya el hecho anunciado (cualquier hecho puede ser interpretado como el primer elemento de una nueva era) y asumimos simplemente el rol de mensajeros del nuevo orden, tratando de explicárselo a los protagonistas de los hechos que deberán conducir a su instalación.

Sería eso tal vez repetir el drama de Erasmo, intentando concretar el momento culminante de la historia basándose en un pupilo, que pretendiendo ser Universal no fue ni el Flamenco ni el Castellano. Que fue un estorbo en las batallas y que sobre todo tenía que consolidar su poder enfrentando a reyes cristianos y no cristianos, católicos y no católicos. Negociando con sus parientes y tratando de equilibrar las diversas dinastías que se reunían en su cabeza.

¿Es posible concretar el nacimiento de una nueva era, cuando las fuerzas que gobiernan la sociedad se manejan hoy como con Carlos V, más cerca de Maquiavelo que de Erasmo? ¿Cuándo los gobernantes tal vez hoy día no sean diferentes del rey que mandó a cortar la cabeza de quien fue el más claro vidente de la utopía de la nueva sociedad (Enrique VIII y Tomás Moro)?

Hay quienes hoy día ven argumentos e indicios para un nuevo mundo, para poder construir una nueva relación con la Naturaleza (Ashby, 1981). El conjunto de literatura que nos anuncia hoy día un nuevo despertar, comprende muy variados autores que unen en sus fuentes nuevos re-descubrimientos de épocas pasadas ${ }^{4}$, y que se alimenta con nuevos descubrimientos de las propias Ciencias Naturales (ver por ejemplo Kapra F, Prigogine, Margulis). Lo cual tal vez tiene un paralelo con los acontecimientos que ya hemos comentado de Copérnico, y luego sucesores como Galileo y Newton. También tenemos pensadores que en un estilo más filosófico nos replantan una discusión sobre el lugar del ser humano en el planeta (tenemos así por ejemplo a un Morin, 1981 y un Berman, 2004).

Pero cabría preguntarnos, ¿no es en realidad todo lo que vemos una repetición del florecimiento renacentista, con el enorme peligro de que nos conduzca a un fracaso o una traición similar a la renacentista? ¿Qué nos hace pensar que ahora, ante la posibilidad de esta nueva era, no vamos a repetir el siglo XV y subsiguientes? ¿Es esto desembocar en nuevas guerras religiosas, nuevos sistemas de persecución y humillación al ser humano? Las similitudes que establecemos parecerían conducirnos hacia una propuesta de desencantar la ilusión del momento presente. Este desencanto que proponemos, tiene sentido, pues el sueño del renacimiento no sólo que fue un fracaso, sino que en más de un aspecto sometió a la humanidad a sufrimientos e injusticias, que tal vez podrían ser calificadas como peores a las medievales.

Pero, ¿fueron los ideales del renacimiento los que llevaron a las guerras religiosas? ¿Fueron los ideales del fin de la edad media los que llevaron a los genocidios? ¿A las guerras ideológicas, a la Inquisición, y luego a las Policías secretas? Nos atrevemos a decir que no y que al contrario, fue la incapacidad del mundo moderno de estar a la altura de una utopía diseñada desde el renacimiento la que alejó la posibilidad de una edad del oro y que al contrario, re-edito con exacerbada crueldad la edad del hierro.

Por ejemplo las ideas de libertad y derecho frente a la autoridad papal se convirtieron en retórica que no impidió que sus defensores adoptaran las propias practicas papales, de manera tal que, por ejemplo, en el caso de Servet este logra escapar de la Inquisición, que se limitó a quemarlo en efigie, pero cayó en manos de la moderna y reformada ciudad calvinista de Ginebra que lo quemó vivo (Villanueva de Sigena).

Con esto queremos alertar respecto del hecho de que las ideas de esperanza, con frecuencia son usadas para encubrir la perversión sádica y re-editar con nuevos bríos y en nuevas dimensiones las fuerzas de la represión y de la destrucción. En realidad el principal enemigo de toda fuerza

4 Por ejemplo con la recuperación del pensamiento oriental que nos recuerda el redescubrimiento de Aristóteles al origen a buena parte del debate sobre la física en el renacimiento. 
que enuncia algo nuevo no esta generalmente en sus enemigos abiertos, sino sobre todo en quienes desde su interior, utilizan el pretexto de lo nuevo, no como una ruta, un camino o una escalera que exige pasos y esfuerzos concretos para ser coronada, sino como pretexto para borrar todo lo conquistado y destruir lo conseguido hasta entonces.

Podría aparecer que asumimos una posición sistemáticamente reaccionaria: no al cambio, puesto que éste desencadena fuerzas incontroladas, las fuerzas de la reforma de la guerra religiosa, de los San Bartolomé, y luego de la Revolución Francesa, con su terror pasando a Hitler y luego el Archipiélago Gualag de Stalin.

Pero no. No es nuestra perspectiva la de refugiarnos en un simple retroceso y negar todo cambio. Al contrario, queremos sugerir una nueva mirada hacia el paso de la modernidad. En efecto, lo que ésta aportó, no fue solamente el conjunto de desastres que hemos descrito. Hay más, hay mucho más, desde la belleza de los propios anuncios que de ella hacen sus precursores, desde la dimensión ética de un Moro que afirma y testimonia sus convicciones con su propia vida, hasta el vasto y rico mundo de las artes. Pero en realidad no es sólo eso. La mente humana se ha visto transformada por el grado de conocimiento que hemos alcanzado sobre la naturaleza. En más de un sentido la promesa del Barroco si se ha cumplido. El conocimiento humano se ha elevando a cumbres impensables. ¿Cómo hubiera vibrado la mente de un Pascal si hubiera tenido acceso a nuestros conocimientos de cosmología? ¿Cuánto asombro habría tenido un Kepler al conocer las orbitas de plutón? y ¿Qué diría Newton frente a las fórmulas de la relatividad? Si, podemos decir que hay promesas cumplidas. Y tal vez las ciencias adulterinas, las prácticas, no merecen ese calificativo por su utilidad, por haber ayudado a atender necesidades humanas, sino por haber servido más a la codicia y al odio entre los humanos.

Hay otras cosas más que el mundo de la modernidad si nos ha dado. Sugiero que es útil pensar en la Ilustración, que nos ha heredado un mundo de derechos. Hoy en día es posible que la humanidad por lo menos piense, se mueva, sufra, por los crímenes que ella misma comete. Hemos construido valores, que a pesar de estar atravesados por contradicciones y conflictos, nos dan una base, nos dan un punto de referencia para saber a donde avanzar.

Tal vez si hay alguna lección que podemos aprender de lo estudiado sobre el renacimiento, y es que si éste hubiera podido ser más fiel a los sueños humanistas que surgían a su interior, germinados en la edad media, los costos de la modernidad habrían sido menores. Si una tolerancia al estilo de Moro, hubiese podido tener espacio, cuanto mas cerca podríamos estar ahora de la edad de oro.

Hoy, como en ese entonces, enfrentamos miles de descubrimientos que enuncian una nueva era. A ratos nos lanzamos en pos de ellos precipitadamente, pero tal vez, la única manera de poder avanzar sin regar a nuestro alrededor sangre y dolor, es recuperar, revalorar nuestra herencia moderna, nuestra herencia de la ilustración, que se enraíza en el renacimiento y en sueños como el erasmiano. 


\section{Bibliografía}

Ashby, E. 1981, Reconciliar el hombre con el Ambiente, Barcelona Blume. Berman, M. 2004, El reencantamiento del Mundo, Cuatro Vientos, Santiago Chile.

Campanella, T. 1967, Metafísica, Bologna (1638).

Capra, F. 2000, La Trama de la Vida, Anagrama Barcelona.

Copérnico, N. 1543, Sobre las revoluciones de los orbes, Norimbergen.

Cotes, R. 1713, Presentación en Newton Isaac Principios Matemáticos de la filosofía de la Naturaleza 1713. Cambridge. UK.

De León, L. 1990, Fray Luis de León Poesías Completas, Gredos Madrid. Fuertes, J. 2001, Saber y Método Genealógico e los Inicios de la Modernidad Logos XXIX 87, pp. 81-105.

2002a, Relatos sobre el hombre en torno a De idis prior de Francisco de Vitoria, Cuadernos Salmantinos de Filosofía. Universidad Pontifica Salamanca XXX.

2002b, "Como vihuela templada, que hace dulce armonía": Imagen del hombre y de la Ciencias en el Renacimiento desde un relato de Pérez de Oliva (1494-1531) Revista Española de Filosofía Medieval 9, pp327 - 337.

2003, Retórica para la Concordia: Viejo Mundo Nuevo Mundo Vieja y Nueva Historia .Revista de Retórica y Teoría de la Comunicación, Año III n5 diciembre, pp. 107-118.

2004a, La Existencia como Filosofía de la Concordia en la Universidad de Salamanca a finales del siglo XVI. Domingo Báñez (1528-1604) En Saberes y Disciplinas en las Universidades Hispánicas, Miscelánea Alfonso IX, Ediciones Universidad Salamanca.

2004b, La filosofía de Ockham y el Inicio de la Modernidad, En Fuertes herreros José Luis y Flores Miguel, Cirilo, Historia de la Filosofía Santiallana, Madrid.

Galilei, G. 1623, El ensayador.

Garcia De Cortazar, J. 1988, La Época Medieval en Artola M. Historia de España Alianza Editorial Madrid.

Morin, E. 1981, Pour sortir du xx siecle, Nathan Paris.

Muñoz, B. 2005, Modelos Culturales : Teoría Sociopolítica de la Cultura, Anthropos, Barcelona.

Newton, I. 1687, Principios matemáticos de la filosofía Natural. Cambridge.

Ockham, W, 1951, Summa logicae William Ockham, editado por Philotheus Boehner St. Bonaventure (New York), The Franciscan Institute.

Rolewink, W. 1993, Fasiculus Temporum, Universidad de León León.

Ruggiero Romano, A. 1971, Los Fundamentos del Mundo Moderno: La edad media tardía, reforma y renacimiento Historia Universal Siglo XXI Madrid.

Vignaux, P. 1938, El Pensamiento en la Edad Media, FCE, España 1999.

Villanueva De Signea. 2006, Miguel Servet - Servet Médico, Teólogo, Filósofo. http://www.villanuevadesigena. com/es/miguel-servet/biografia-servetus.htm. 